\title{
Clinical and Molecular Characterization of the 20q11.2 Microdeletion Syndrome: Six New Patients
}

Guillaume Jedraszak, ${ }^{1,2 *}$ Bénédicte Demeer, ${ }^{1}$ Michèle Mathieu-Dramard, ${ }^{1}$ Joris Andrieux, ${ }^{3}$ Aline Receveur, ${ }^{2}$ Astrid Weber, ${ }^{4}$ Una Maye, ${ }^{5}$ Nicola Foulds, ${ }^{6}$ IK Temple, ${ }^{7}$ John Crolla, ${ }^{8}$ Marie-Pierre Alex-Cordier, ${ }^{9}$ Damien Sanlaville, ${ }^{10,11}$ Lisa Ewans, ${ }^{12}$ Meredith Wilson, ${ }^{12}$ Ruth Armstrong, ${ }^{13}$ Amanda Clarkson, ${ }^{14}$ Henri Copin, ${ }^{2}$ and Gilles Morin ${ }^{1}$

${ }^{1}$ Unité de Génétique Médicale et Oncogénétique, Centre Hospitalier Universitaire Amiens Picardie, Amiens, France

${ }^{2}$ Laboratoire de Cytogénétique et Biologie de la Reproduction, Centre Hospitalier Universitaire Amiens Picardie, Amiens, France

${ }^{3}$ Laboratoire de Génétique Médicale Hôpital Jeanne de Flandre, Centre Hospitalier Régional Universitaire de Lille, Lille, France

${ }^{4}$ Department of Clinical Genetics Alder Hey Children's Hospital, Royal Liverpool University Hospital, Liverpool, United Kingdom

${ }^{5}$ Cytogenetics Department Liverpool Women's Hospital, NHS Foundation Trust Liverpool, Liverpool, United Kingdom

${ }^{6}$ Wessex Clinical Genetics ServicePrincess Anne Hospital, University Hospital Southampton, Southampton, United Kingdom

'Human Genetics and Genomic Medicine, Faculty of Medicine, University of Southampton, Southampton, United Kingdom

${ }^{8}$ Wessex Regional Genetics Laboratory, NHS Foundation Trust Salisbury, Salisbury, United Kingdom

${ }^{9}$ Service de Génétique Clinique, Centre Hospitalier Universitaire de Lyon, Lyon, France

${ }^{10}$ Hospices Civils de Lyon, Service de Génétique Clinique, Centre Hospitalier Universitaire de Lyon, Lyon, France

${ }^{11}$ INSERM, U1028, CNRS, UMR5292, TIGER Team UCBL1, Lyon, France

${ }^{12}$ Clinical Genetics Unit The Children's Hospital at Westmead, Division of Genetic Medicine University of Sydney, Australia

${ }^{13}$ East Anglian Medical Genetics Service, Addenbrooke's Hospital Cambridge, Cambridge, United Kingdom

${ }^{14}$ Regional Genetics Laboratory, Addenbrooke's Hospital, Cambridge, United Kingdom

Manuscript Received: 28 March 2014; Manuscript Accepted: 23 October 2014

Interstitial microdeletions of $20 \mathrm{q}$ chromosome are rare, only 17 patients have been reported in the literature to date. Among them, only six carried a proximal 20q11.21-q11.23 deletion, with a size ranging from 2.6 to $6.8 \mathrm{Mb}$. The existence of a $20 \mathrm{q} 11.2$ microdeletion syndrome has been proposed, based on five previously reported cases that displayed anomalies of the extremities, intellectual disability, feeding difficulties, craniofacial dysmorphism and variable malformations. To further characterize this syndrome, we report on six new patients with $20 \mathrm{q} 11.2$ microdeletions diagnosed by whole-genome array-based comparative genomic hybridization. These patient reports more precisely refined the phenotype and narrowed the minimal critical region involved in this syndrome. Careful clinical assessment confirms the distinctive clinical phenotype. The craniofacial dysmorphism consists of high forehead, frontal bossing, enophthalmos, and midface hypoplasia. We have identified a 1.62 megabase minimal critical region involved in this syndrome encompassing three genes - GDF5, EPB41L1, and SAMHD1-which are strong candidates for different aspects of the phenotype. These results support that $20 \mathrm{q} 11.2$ microdeletion syndrome is a new contiguous gene deletion syndrome with a recognizable phenotype. $\odot 2014$ Wiley Periodicals, Inc.

Key words: 20q11.2 deletion syndrome; 20q11.21q11.23 deletion; Anomalies of hands; Anomalies of feet; Facial dysmorphisms; Contiguous gene deletion syndrome; GDF5

\section{How to Cite this Article:}

Jedraszak G, Demeer B, Mathieu-Dramard M, Andrieux J, Receveur A, Weber A, Maye U, Foulds N, Temple IK, Crolla J, AlexCordier M-P, Sanlaville D, Ewans L, Wilson $\mathrm{M}$, Armstrong R, Clarkson A, Copin H, Morin G. 2014. Clinical and molecular characterization of the 20q11.2 microdeletion syndrome: Six new patients. Am J Med Genet Part A. 9999A:1-8.

Conflicts of interest: None.

${ }^{*}$ Correspondence to:

Guillaume Jedraszak, Département de Génétique, CBH, CHU Amiens Picardie, Avenue R. Laennec, 80,054 AMIENS Cedex 1, France.

E-mail: guillaumejedraszak@yahoo.fr

Article first published online in Wiley Online Library

(wileyonlinelibrary.com): 00 Month 2014

DOI 10.1002/ajmg.a.36882 


\section{INTRODUCTION}

Interstitial microdeletions of the chromosome $20 \mathrm{q}$ region are rare. To our knowledge, only 17 patients have been reported in the literature to date [Fraisse et al., 1981 Petersen et al., 1987; Porfirio et al., 1987; Shabtai et al., 1993; Aldred et al., 2002; Chen et al., 2005; Geneviève et al., 2005; Callier et al., 2006; Borozdin et al., 2007; Iqbal and Al-Owain, 2007; Hiraki et al., 2011; Gervasini et al., 2013; Iourov et al., 2013; Santoro et al., 2013; Posmyk et al., 2014] and only six of these patients carried a proximal 20q11.2 deletion, with a size ranging from 2.6 to $6.8 \mathrm{Mb}$ [Callier et al., 2006; Iqbal and AlOwain, 2007; Hiraki et al., 2011; Gervasini et al., 2013; Iourov et al., 2013; Posmyk et al., 2014]. Intellectual disability, craniofacial dysmorphism, anomalies of the extremities and feeding difficulties are recurrent clinical features in these patients, suggesting a recognizable microdeletion syndrome. We report on a study of six new patients harbouring a de novo 20q11.21-q11.23 microdeletion; these patients presented with a suggestive phenotype. Comparison of the deleted regions in these patients allowed more precise characterization of the critical region responsible for the phenotype, and discussion of genotype/phenotype correlations.

\section{CLINICAL REPORTS}

The phenotypic features of the six new unrelated patients and the five previously reported patients with 20q11.2 microdeletion are summarized in Table I. Clinical data and informed consents were obtained from all patients or their legal representatives.

\section{Patient 1}

Patient 1 was a 15-year-old boy, the second child of unrelated healthy parents with no family history of malformation. He was born at 41 weeks of gestation (WG) after an uneventful pregnancy. At birth, he weighed $3,030 \mathrm{~g}\left(45^{\text {th }}\right.$ centile) and presented with global hypotonia, poor movements, a right supernumerary nipple, facial dysmorphism (Fig. 1 and Table I) and anomalies of the extremities (Figs. 2 and 3 , and Table I). The subsequent course was marked by delayed psychomotor acquisitions with moderate intellectual disability. At age 15 , he was unable to read or write despite management in a specialized school, and he was unable to dress by himself. He had mild features of autism spectrum disorder such as hand and finger biting, avoidance of eye contact, and social difficulties. Changes in facial dysmorphism were noted during the follow-up with the disappearance of microretrognathia and short philtrum, and the appearance of deep-set eyes and midface hypoplasia (Fig. 1). Growth was within normal range with a height of $180 \mathrm{~cm}$ ( $90^{\text {th }}$ centile), weight of $75 \mathrm{~kg}\left(90^{\text {th }}\right.$ centile $)$ and head circumference of $59 \mathrm{~cm}\left(90^{\text {th }}\right.$ centile) at the age of 15 . Hearing tests showed a $50 \mathrm{~dB}$ deficit on the right side. Ophthalmological examination, visual evoked potentials, electroencephalogram, brain MRI, electrocardiogram, abdominal ultrasound and echocardiography were normal.

\section{Patient 2}

Patient 2 was a 5.5-year-old boy with no family history of malformation. He was born at $40 \mathrm{WG}$ after a pregnancy without medical supervision. Birth weight was $2,700 \mathrm{~g}\left(20^{\mathrm{th}}\right.$ centile). He presented with global hypertonia, anomalies of both hands and feet, and facial dysmorphism (Table I). Anomalies of the extremities consisted of fifth finger clinodactyly, left-sided single transverse palmar crease, and talipes varus. The subsequent course was marked by severe psychomotor and language delay: he began sitting over 1 year of age, waking independently at the age of 3 years, and spoke his first words over 5 years of age. When he was 5.5 years old, height was $107.6 \mathrm{~cm}$ ( $9^{\text {th }}$ centile), weight was $21.6 \mathrm{~kg}\left(50^{\text {th }}-75^{\text {th }}\right.$ centile) and head circumference was $53 \mathrm{~cm}$ ( $50^{\text {th }}$ centile). Facial dysmorphism consisted of facial asymmetry, frontal bossing, deep-set eyes, midface hypoplasia, and short philtrum. Ophthalmological examination showed intermittent strabismus. Hearing testing was normal. No other malformations were detected.

\section{Patient 3}

Patient 3 was a 6-year-old boy with no family history of malformation. He was born at $39 \mathrm{WG}$ after a pregnancy without medical supervision with a birth weight of $3,385 \mathrm{~g}\left(75-90^{\mathrm{th}}\right.$ centile $)$. At birth, he presented with global hypotonia, anomalies of the extremities (Fig. 2 and Table I), mild pectus carinatum and facial dysmorphism (Fig. 1 and Table I). The subsequent course was marked by developmental delay: he was able to sit from the age of 1 year and able to walk independently from the age of 2.5 years. Language was more severely affected: the first single words appeared at the age of 2 years 3 months. He was able to read a few words from the age of 6 years after management in a specialized school. At the age of 6 years, height was $104 \mathrm{~cm}\left(0.4^{\text {th }}-2^{\text {nd }}\right.$ centile $)$, weight was $15.9 \mathrm{~kg}\left(0.4^{\text {th }}-2^{\text {nd }}\right.$ centile) and head circumference was $50.5 \mathrm{~cm}\left(2^{\text {nd }}-9^{\text {th }}\right.$ centile $) . X-$ rays of the extremities showed shortening of proximal and middle phalanges of second fingers, shortening of the middle phalanges of fifth fingers, and eleven pairs of ribs. He did not present any hearing anomalies or other malformations.

\section{Patient 4}

Patient 4 was a 2.5-year-old boy born at 32 WG after a spontaneous triplet trichorionic triamniotic pregnancy. At birth, weight was $1,210 \mathrm{~g}\left(2^{\text {nd }}\right.$ centile $)$ and head circumference was $27.5 \mathrm{~cm}\left(2^{\text {nd }}-9^{\text {th }}\right.$ centile). He presented with global hypotonia, facial dysmorphism (Fig. 1 and Table I) and anomalies of the extremities (Fig. 2 and Table I). The first weeks of life were marked by feeding difficulties and oesophageal reflux requiring gastrostomy. At the age of 8 months, facial dysmorphism consisted of sparse hair, broad and high forehead, hypertelorism, mild downslanting palpebral fissures, deep-set eyes, midface hypoplasia, short philtrum, microretrognathia, and small ears. When he was 2.5 years old, height was $86.5 \mathrm{~cm}\left(9^{\text {th }}-25^{\text {th }}\right.$ centile $)$, weight was $11.7 \mathrm{~kg}\left(9^{\text {th }}\right.$ centile $)$ and head circumference was $48 \mathrm{~cm}$ ( $2^{\text {nd }}$ centile). Facial dysmorphism had changed with disappearance of microretrognathia and appearance of hypoplastic alae nasi and long columella (Fig. 1). The subsequent course was marked by severe psychomotor retardation: he was unable to stand at 2.5 years of age and was delayed in oral language (limited to three words at the age of two years). Growth was normal. At birth, brain MRI showed delayed myelination and thickening of the ventricles. He presented no hearing impairment or other malformations. 


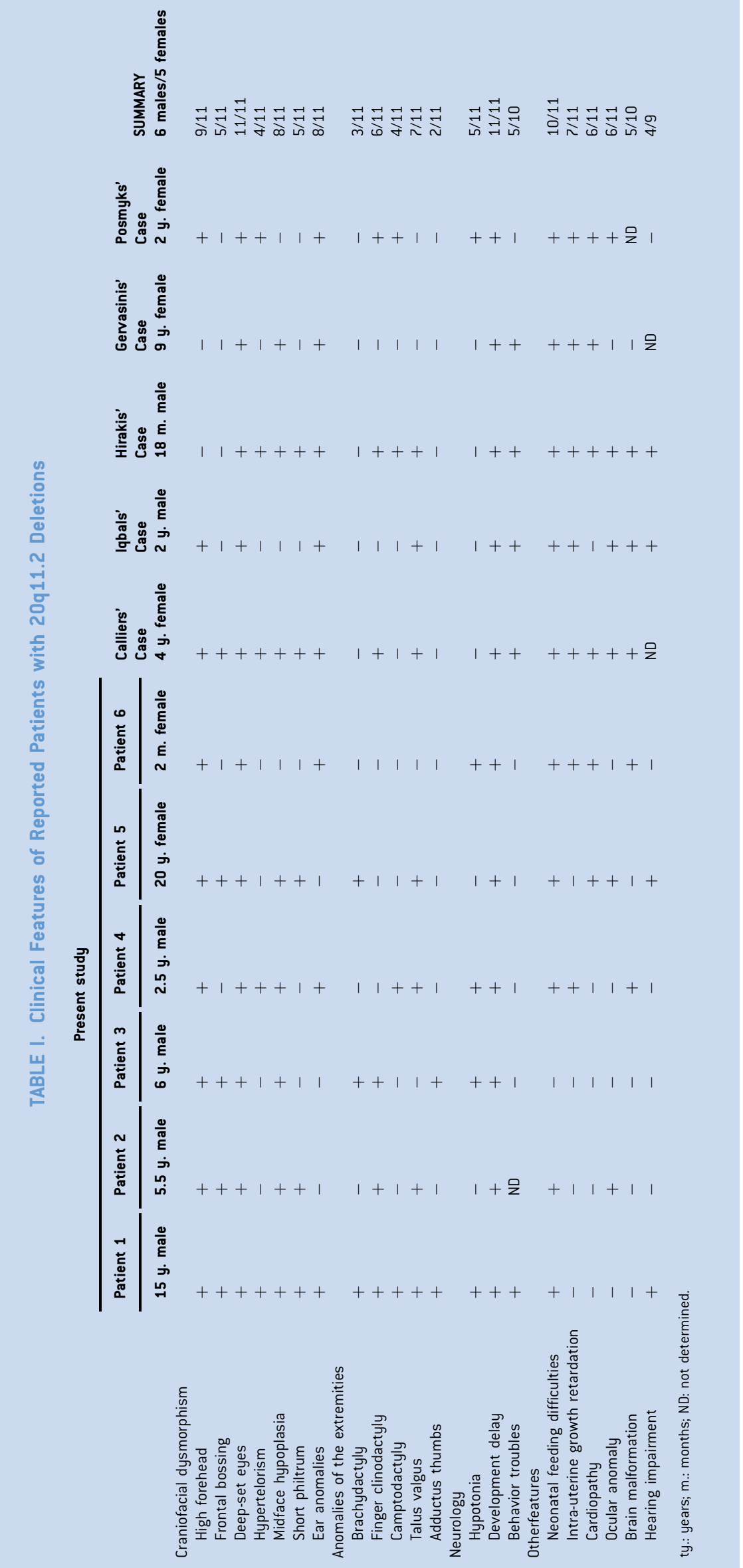




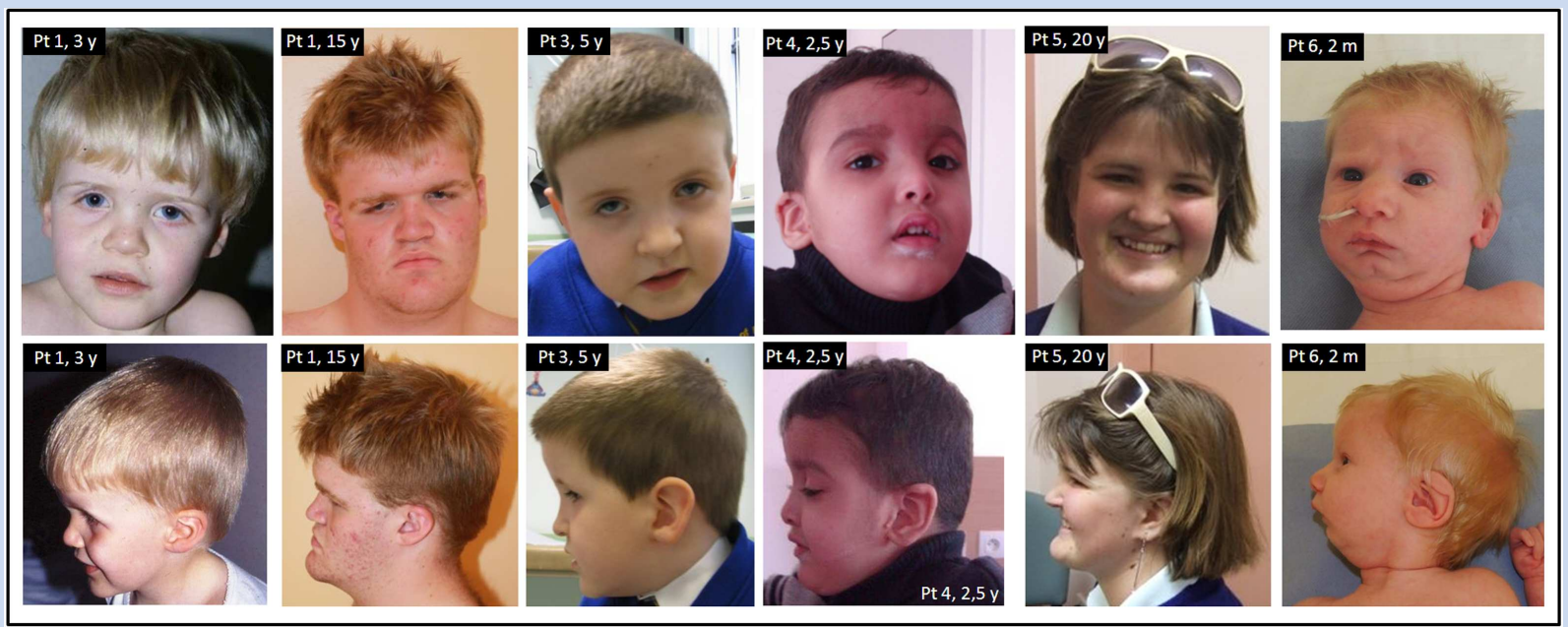

FIG. 1. Facial dysmorphism. Common facial features are broad and high forehead with frontal bossing, deep-set eyes, midface hypoplasia and ears anomalies. Patient 6 also had a microretrognathia.

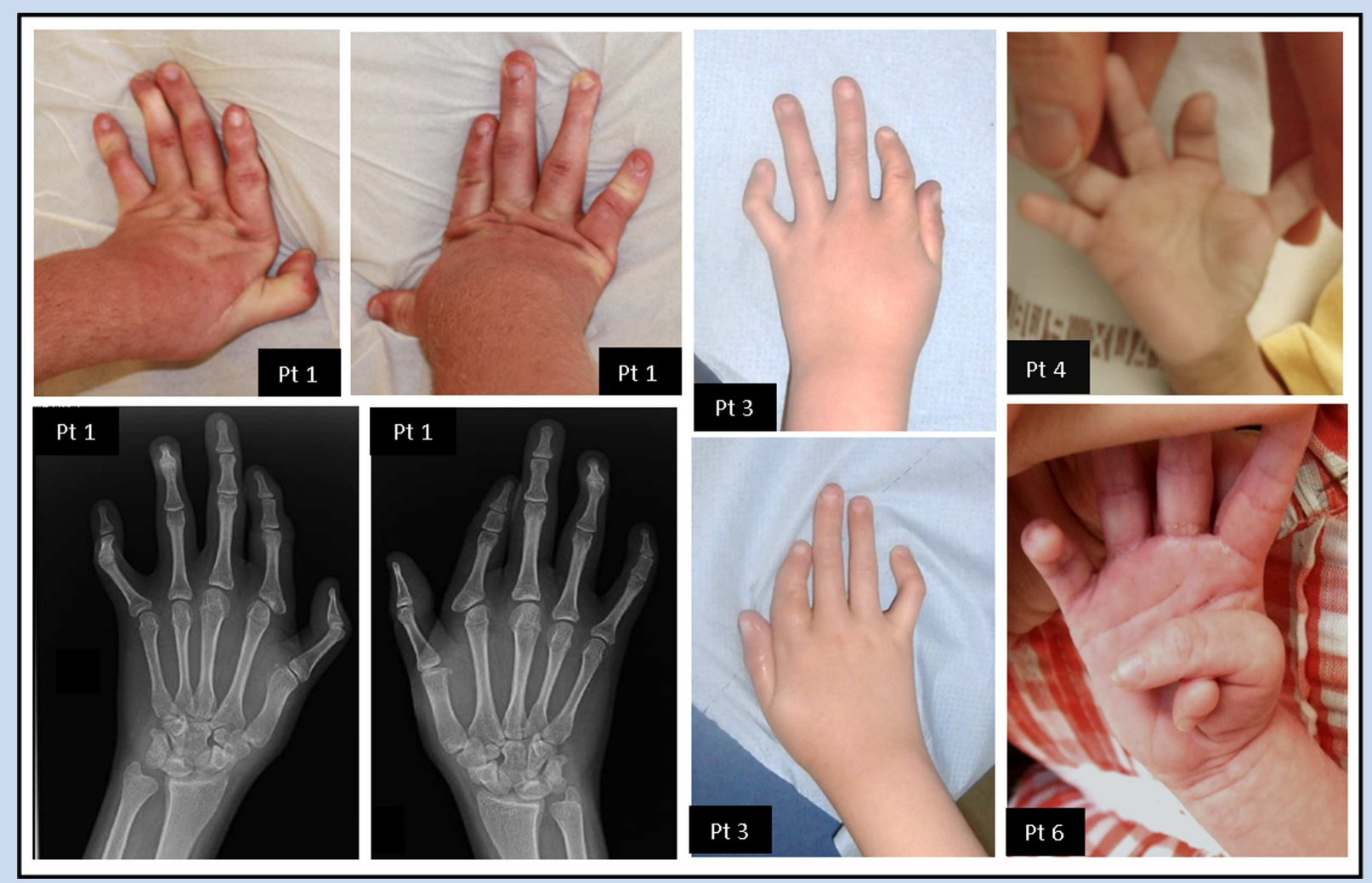

FIG. 2. Hand anomalies in Patients 1, 3, and 6. Hand anomalies. Common features are 2nd [3rd] and 5th fingers brachydactyly, camptodactyly and clinodactyly. Patient 6 had right pre-axial polydactyly and long fingers. 


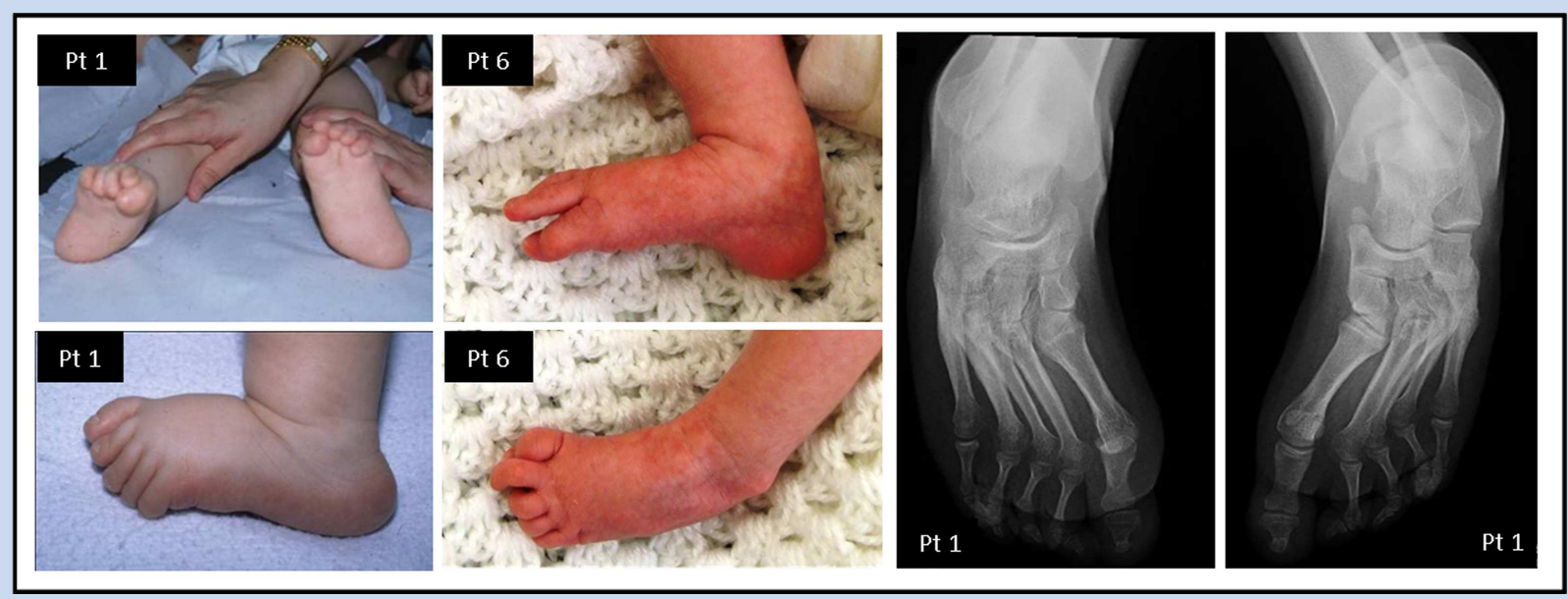

FIG. 3. Feet anomalies in Patients 1 and 6. Patient 1 had bilateral talus valgus and hallux adductus. Patient 6 had long and overlapping toes.

\section{Patient 5}

Patient 5 was a 20-year-old woman with no family history of psychomotor delay or malformation. She was born at term after an uneventful pregnancy. At birth, weight was 3,000 $\mathrm{g}\left(10^{\text {th }}\right.$ centile) and length was $51 \mathrm{~cm}\left(50^{\text {th }}\right.$ centile $)$. Multiple congenital anomalies were diagnosed, including total anomalous pulmonary venous return requiring surgical treatment in the first week of life, bilateral congenital talus valgus, hip dysplasia, right sacroiliac pit and covered anus and facial dysmorphism (Fig. 1 and Table I). The subsequent course was marked by mild developmental delay. No delay of motor acquisitions was observed. Language developed from the age of 3-4 years, and reading and writing were acquired only from the age of 8 years, after intensive management in a specialized school. Precocious puberty and an excessive weight gain were noted during adolescence due to food-seeking behavior. At the age of 20 , she was able to read and write, had a job and lead a relatively independent life. Height was $157 \mathrm{~cm}\left(10^{\text {th }}-25^{\text {th }}\right.$ centile), and weight was $57 \mathrm{~kg}\left(25^{\text {th }}-50^{\text {th }}\right.$ centile). Changes in facial dysmorphism were noted: the midface hypoplasia became more obvious with time. She also had tapered fingers and narrow calves. Dermatological examination revealed multiple melanocytic naevi and lentigines. Ophthalmological examination revealed unilateral astigmatism and ptosis. Hearing tests showed bilateral high frequency hearing loss. She had no other obvious malformations.

\section{Patient 6}

Patient 6 was a 2-month-old girl. Prenatal ultrasound found mild intra-uterine growth restriction and oligohydramnios from $27 \mathrm{WG}$. She was born at 39 WG with a birth weight of $2,268 \mathrm{~g}\left(0.4^{\text {th }}-2^{\text {nd }}\right.$ centile). She presented with global hypotonia, facial dysmorphism (Fig. 1 and Table I) and digital anomalies (Fig. 2 and 3, and Table I). During the first two months of life, she experienced feeding difficulties with failure to thrive in a context of gastroesophageal reflux and seizures. When she was two months old, weight was $2,900 \mathrm{~g}\left(0.4^{\text {th }}-2^{\text {nd }}\right.$ centile $)$ and head circumference was $35 \mathrm{~cm}$ $\left(0.4^{\text {th }}-2^{\text {nd }}\right.$ centile $)$. Her hand malformations consisted of right pre-axial polydactyly and long fingers. She had long, overlapping toes (Fig. 3). Brain MRI showed atrophy of the left hemisphere, and unilateral end-stage periventricular leukomalacia. Echocardiography revealed atrial septal defect, mitral incompetence and pulmonary hypertension. She had no other obvious malformations.

\section{METHODS}

Chromosomal analyses were performed for all patients after obtaining informed consent according to local legislation in each country. Conventional karyotypes, FISH and quantitative PCR analyses were performed according to standard methods on samples of peripheral blood lymphocytes. Array CGH analyses were performed using a $44 \mathrm{~K}$ array for Patients 1 and 3 (Agilent Technologies, Santa Clara, CA, USA), $180 \mathrm{~K}$ array for Patient 4 (Agilent Technologies, Santa Clara, CA, USA), and a $60 \mathrm{~K}$ array (Bluegnome ISCA Cytochip, Cambridge, UK) for Patients 2 and 5. A SNP array using an Affymetrix GeneChip 6.0 array (Affymetrix, Santa Clara, CA, USA) was performed for Patient 6. Confirmation of these results and investigation of inheritance were performed by analysing parental samples when available, using quantitative PCR (Patients 1 and 4), FISH analyses (Patients 2, 3 , and 5), or karyotype (Patient 6).

DNA sequence information for patients is presented according to the UCSC Genome Browser (http://genome.ucsc.edu/; February 2009 Assembly, hg19).

\section{RESULTS}

Cytogenetics analyses were performed to explore a malformation syndrome in each case. No anomalies were found on conventional karyotypes. Array CGH analyses found a microdeletion of the 20q11.2 chromosomal region in all patients, with sizes ranging 
from 2.24 Mb to 7.7 Mb (Table II). Array-CGH also excluded the involvement of another chromosomal imbalance in the phenotype. Patients 1 to 4 , who had a very similar phenotype, allow us to define a minimal critical region measuring $1.62 \mathrm{Mb}(33,962,025-$ 35,580,928)(hg19) (Fig. 4). This region encompasses 29 genes according to the UCSC Genome Browser. Three of these genes are referenced in the OMIM database: GDF5, EPB41L1 and $S A M H D 1$. All breakpoints of the deleted regions were unique, suggesting that these deletions were not generated by a non-allelic homologous recombination mechanism. The deleted region in Patient 5 did not include EPB41L1, and the deleted region in patient 6 did not include GDF5, as showed in Figure 4.

The de novo occurrence of the deletions was confirmed for Patients 1, 2, 4, 5 and 6 by cytogenetic analysis of their parents. An inherited form could not be excluded in Patient 3: the mother did not carry the deletion and the father could not be tested.

\section{DISCUSSION}

We report on six new patients with a 20 q11.2 microdeletion. They shared common clinical features with previously reported patients. Array CGH analyses refined the minimal critical deleted interval to a $1.62 \mathrm{Mb}$ region.

Only five patients with de novo interstitial 20q11.2 deletions have been previously reported, and their cytogenetic results are summarized in Figure 4 [Callier et al., 2006; Iqbal and Al-Owain, 2007; Hiraki et al., 2011; Gervasini et al., 2013 ; Posmyk et al., 2014]. Another patient reported by Iourov et al. [2013] harboured a more proximal deletion, with a different phenotype, and will be excluded from the discussion.

Comparison of the clinical data of our 6 patients and those of the five previously reported patients support the idea that the $20 \mathrm{q} 11.2$ microdeletion causes a recognizable clinical phenotype. Ten of the 11 patients presented with anomalies of the extremities. Both hands and feet were affected with extremely variable degrees of severity. The most common signs in these patients were finger clinodactyly (6/11), camptodactyly (4/11), brachydactyly (3/11) and feet malposition (7/11). The anomalies observed in Patient 1 can be classified as type A2 brachydactyly and those of Patient 3 can be classified as type $\mathrm{C}$ brachydactyly. Two patients presented with pre-axial polydactyly associated with other distal anomalies; only Patient 6 presented with isolated pre-axial polydactyly. Surprisingly, the patient reported by Gervasini et al. [2013] had no anomaly of the extremities. Ten of the 11 patients presented with feeding difficulties and failure to thrive during the first weeks of life. Associated gastrointestinal anomalies were observed in 6 patients, including gastroesophageal reflux, pyloric stenosis and oesophageal hiatus hernia. Psychomotor delay was present in all 11 patients: moderate to severe delay in both motor and language acquisitions were noted in 10 patients. Only Patient 5 presented with mild intellectual disability. A recognizable craniofacial dysmorphism was suggested, which comprised of high forehead, enophthalmos, abnormal ears, short philtrum and microretrognathia in infants. Microretrognathia had resolved in the oldest patients and, inversely, the chin became more prominent and midface hypoplasia became more apparent. Furthermore, patients with 20q11.2 microdeletion exhibit occasional findings of variable growth (7/11), behavioral disorders $(5 / 10)$, hearing impairment (4/9) and inconsistent malformations of the heart $(6 / 11)$, eye $(6 / 11)$ and brain (5/10) were also noted (Table I).

At least three genes included in the common deleted region could probably be responsible for a part of the associated phenotype. Growth/Differentiation factor 5 (GDF5) - OMIM 601146-encodes a secreted growth factor that plays a regulatory role in embryonic skeletal and joint development in mice and chicks by modulation of the BMP pathway [Storm and Kingsley, 1996; Merino et al., 1999]. Mutations of this gene induce various syndromes characterized by skeletal malformations, depending on the site of the mutations and their consequences for protein function [Temtamy and Aglan, 2008; Mundlos, 2009]. There is evidence that haploinsufficiency of GDF5 is the mechanism responsible for type C brachydactyly, as all the reported mutations are frameshift or missense heterozygous mutations leading to loss of function of the protein [Everman et al., 2002; Yang et al., 2008]. All patients, except for Patients 1 and 3, presented with more variable associations of anomalies of the extremities, suggesting another molecular pathogenesis in the case of entire GDF5 deletions. Patient 6 harbored a deletion that did not encompass GDF5, and she presented with a different phenotype of the extremities with unilateral pre-axial polydactyly and long fingers. The patients reported by Hiraki et al. [2011] and Posmyk et al. [2014] also presented with pre-axial polydactyly, suggesting the possible implication of another unknown genetic factor located in this chromosomal region. Some heterozygous GDF5 mutations are associated with hearing impairment, probably due to abnormalities of middle ear bones. This possibly explains the hearing impairment observed in four patients. GDF5 may also have

TABLE II. Summary of the Deleted Region (hg19)

$\begin{array}{ll}\text { Patient } & \text { Microarray } \\ 1 & \text { Agilent 44K } \\ 2 & \text { ISCA Cytochip 60K } \\ 3 & \text { Agilent 44K } \\ 4 & \text { Agilent 180K } \\ 5 & \text { ISCA Cytochip 60K } \\ 6 & \text { AffymetrixGeneChip 6.0 }\end{array}$

Array CGH results of patients with deletion 20q11.2.

Deleted region
chr20:33,962,025-36,768,739
chr20:32,945,492-37,263,920
chr20:33,834,793-37,945,599
chr20:33,097,682-35,580,928
chr20:32,118,663-34,361,435
chr20:34,194,054-41,958,122

Size

$2.8 \mathrm{Mb}$

$4.3 \mathrm{Mb}$

$4.1 \mathrm{Mb}$

$2.48 \mathrm{Mb}$

$2.24 \mathrm{Mb}$

7.7 $\mathrm{Mb}$
Inheritance

de novo

de novo

not determined

de novo

de novo

de novo 


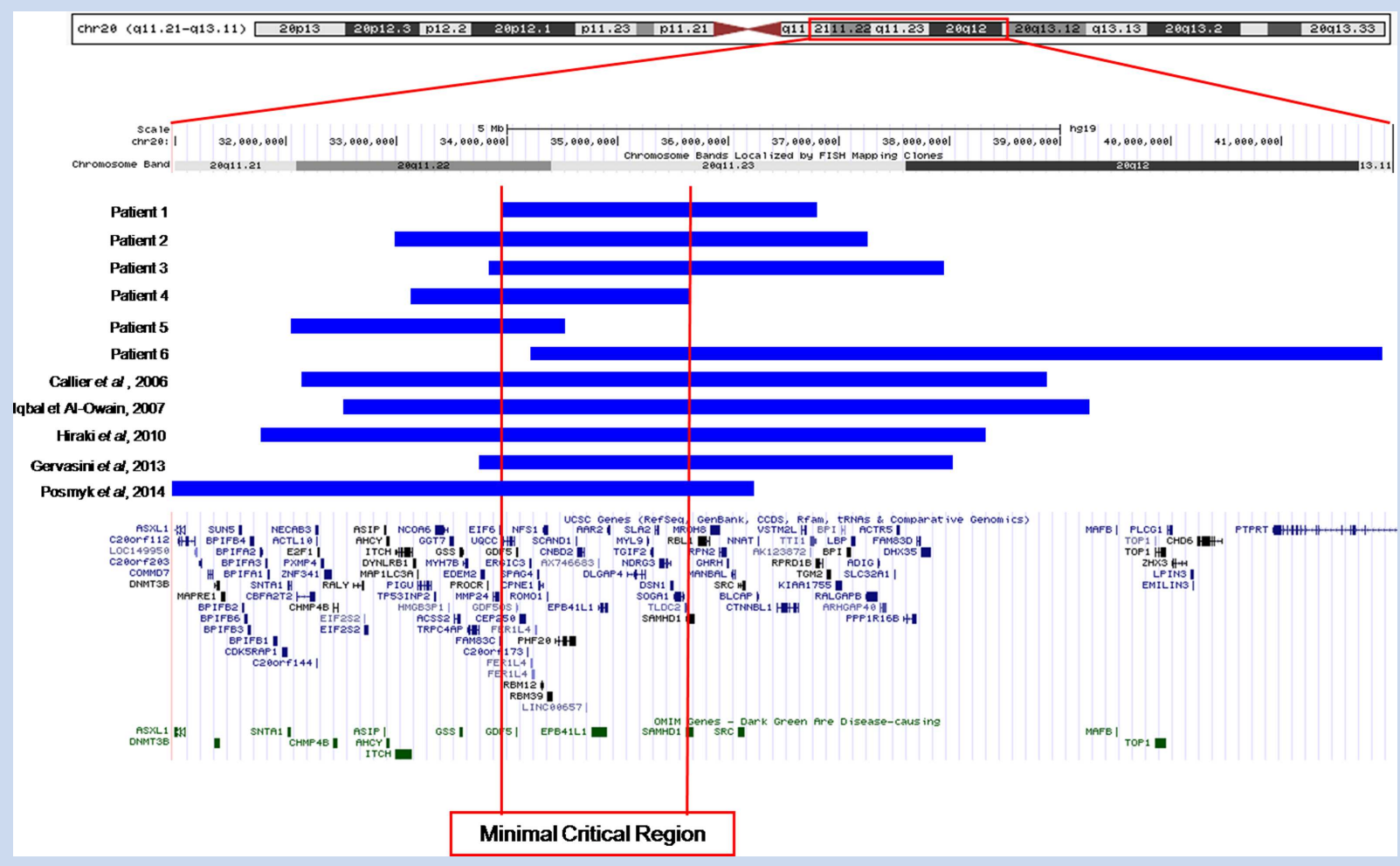

FIG. 4. Comparison of the deleted regions. Array CGH analyses refined the minimal critical region to a $1.62 \mathrm{Mb}$ deletion, between $33,962,025$ and 35,580,928 (hg19) (UCSC Genome Browser).

other pleiotropic effects: the influence of GDF5 on dendrite size and morphology was demonstrated in a murine model, which could explain part of the neurological phenotype observed in these patients [Osório et al., 2013].

Erythrocyte Membrane Protein Band 4.1-Like 1 (EPB41L1) OMIM 602879-is included in the critical deleted region and was deleted in ten patients. EPB41L1 encodes a neuronal cytoskeletal protein, called $4.1 \mathrm{~N}$, that binds an AMPA receptor, GLUR1, and regulates its expression at excitatory synapses [Shen et al., 2000]. A missense loss-of-function mutation of EPB41L1 has been reported in one case of nonsyndromic intellectual disability syndrome (MRD11-OMIM 614257): the patient presented with hypotonia and severe intellectual disability but with no cerebral malformations [Hamdan et al., 2011]. It can be hypothesized that haploinsufficiency of EPB41L1 results in decreased function of $4.1 \mathrm{~N}$ and is responsible for part of the neurological phenotype of patients with a 20q11.2 deletion. Patient 5 harbored a deletion that did not encompass EPB41L1, which could possibly explain her less severe neurological phenotype.

SAMHD1-OMIM 606754-is the third gene of interest included in the common deleted region. Bi-allelic mutations and/or deletions in SAMHD1 have been associated with Aicardi-Goutieres syndrome [Rice et al., 2009; Leshinsky-Silver et al., 2011]. Heterozygous mutations in $S A M H D 1$ are also known to be responsible for a late-onset form of systemic lupus erythematosus and retinal vasculopathy with cerebral leukodystrophy [Ravenscroft et al., 2011]. Deletion of SAMHD1 could explain the cerebral malformations (cerebral atrophy in the three first patients reported, periventricular leukomalacia in Patient 6), and the retinal dysplasia observed in the patients reported by Hiraki et al. [2011] and Posmyk et al. [2014]. While systemic lupus erythematosus has not been reported in the literature to date in any patients with $20 \mathrm{q} 11.2$ deletions, regular and long-term follow up would be important to identify the potential onset of systemic lupus erythematosus in these patients.

In conclusion, these findings confirm that deletion of chromosome $20 \mathrm{q} 11.2$ is responsible for a recognizable microdeletion syndrome comprising anomalies of the extremities, distinctive facial dysmorphism, intellectual disability, neonatal feeding difficulties and hearing impairment. We hypothesize that three genes are involved in the phenotype: GDF5 for anomalies of the extremities and hearing impairment, EPB41L1 for intellectual disability, and SAMHD1 for cerebral malformation and retinal dysplasia. This study supports that the 20q11.21q11.23 microdeletion syndrome may be a newly recognized contiguous gene deletion syndrome.

\section{ACKNOWLEDGMENTS}

We wish to express our sincere gratitude to the patients and their families for their participation. 


\section{REFERENCES}

Aldred MA, Aftimos S, Hall C, Waters KS, Thakker RV, Trembath RC, Brueton L. 2002. Constitutional deletion of chromosome 20q in two patients affected with albright hereditary osteodystrophy. Am. J. Med. Genet 113:167-172.

Borozdin W, Graham JM, Jr, Böhm D, Bamshad MJ, Spranger S, Burke L, Leipoldt M, Kohlhase J. 2007. Multigene deletions on chromosome 20q13.13-q13.2 including SALL4 result in an expanded phenotype of Okihiro syndrome plus developmental delay. Hum. Mutat 28:830.

Callier P, Faivre L, Marle N, Thauvin-Robinet C, Sanlaville D, Gosset P, Prieur M, Labenne M, Huet F, Mugneret F. 2006. Major feeding difficulties in the first reported case of interstitial 20q11.22-q12 microdeletion and molecular cytogenetic characterization. Am. J. Med. Genet. A 140A: $1: 1859-1863$.

Chen C-P, Lin S-P, Lin C-C, Li Y-C, Chern S-R, Chen W-M, Lee C-C, Hsieh L-J, Wang W. 2005. Perinatal findings and molecular cytogenetic analysis of de novo partial trisomy 16q (16q22.1->qter) and partial monosomy 20q (20q13.3->qter). Prenat. Diagn 25:112-118.

Everman DB, Bartels CF, Yang Y, Yanamandra N, Goodman FR, MendozaLondono JR, Savarirayan R, White SM, Graham JM, Jr, Gale RP, Svarch E, Newman WG, Kleckers AR, Francomano CA, Govindaiah V, Singh L, Morrison S, Thomas JT, Warman ML. 2002. The mutational spectrum of brachydactyly type C. Am. J. Med. Genet 112:291-296.

Fraisse J, Bertheas MF, Frère F, Lauras B, Rolland MO, Brizard CP. 1981. [Partial monosomy 20q: a new syndrome. Regional assignment of the adenosine deaminase (ADA) locus on 20q132 (author's transl)]. Ann. Génétique 24:216-219.

Geneviève D, Sanlaville D, Faivre L, Kottler M-L, Jambou M, Gosset P, Boustani-Samara D, Pinto G, Ozilou C, Abeguilé G, Munnich A, Romana S, Raoul O, Cormier-Daire V, Vekemans M. 2005. Paternal deletion of the GNAS imprinted locus (including Gnasxl) in two girls presenting with severe pre- and post-natal growth retardation and intractable feeding difficulties. Eur. J. Hum. Genet. EJHG 13:1033-1039.

Gervasini C, Picinelli C, Azzollini J, Rusconi D, Masciadri M, Cereda A, Marzocchi C, Zampino G, Selicorni A, Tenconi R, Russo S, Larizza L, Finelli P. 2013. Genomic imbalances in patients with a clinical presentation in the spectrum of Cornelia de Lange syndrome. BMC Med. Genet 14:41.

Hamdan FF, Gauthier J, Araki Y, Lin D-T, Yoshizawa Y, Higashi K, Park AR, Spiegelman D, Dobrzeniecka S, Piton A, Tomitori H, Daoud H, Massicotte C, Henrion E, Diallo O, Group, Shekarabi M, Marineau C, Shevell M, Maranda B, Mitchell G, Nadeau A, D’Anjou G, Vanasse M, Srour M, Lafrenière RG, Drapeau P, Lacaille JC, Kim E, Lee J-R, Igarashi K, Huganir RL, Rouleau GA, Michaud JL. 2011. Excess of de novo deleterious mutations in genes associated with glutamatergic systems in nonsyndromic intellectual disability. Am. J. Hum. Genet 88:306-316.

Hiraki Y, Nishimura A, Hayashidani M, Terada Y, Nishimura G, Okamoto N, Nishina S, Tsurusaki Y, Doi H, Saitsu H, Miyake N, Matsumoto N. 2011. A de novo deletion of 20q11.2-q12 in a boy presenting with abnormal hands and feet, retinal dysplasia, and intractable feeding difficulty. Am. J. Med. Genet. A 155A:409-414.

Iourov IY, Vorsanova SG, Kurinnaia OS, Yurov YB. 2013. An interstitial 20q11. 21 microdeletion causing mild intellectual disability and facial dysmorphisms. Case Rep. Genet. 2013. Article ID: 353028.
Iqbal MA, Al-Owain M. 2007. Interstitial del(20)(q11.2q12) - clinical and molecular cytogenetic characterization. Am. J. Med. Genet. A 143A: $1: 1880-1884$.

Leshinsky-Silver E, Malinger G, Ben-Sira L, Kidron D, Cohen S, Inbar S, Bezaleli T, Levine A, Vinkler C, Lev D, Lerman-Sagie T. 2011. A large homozygous deletion in the SAMHD1 gene causes atypical AicardiGoutieres syndrome associated with mtDNA deletions. Eur. J. Hum. Genet. EJHG 19:287-292.

Merino R, Macias D, Gañan Y, Economides AN, Wang X, Wu Q, Stahl N, Sampath KT, Varona P, Hurle JM. 1999. Expression and function of Gdf5 during digit skeletogenesis in the embryonic chick leg bud. Dev. Biol 206:33-45.

Mundlos S. 2009. The brachydactylies: a molecular disease family. Clin. Genet 76:123-136.

Osório C, Chacón PJ, Kisiswa L, White M, Wyatt S, Rodríguez-Tébar A, Davies AM. 2013. Growth differentiation factor 5 is a key physiological regulator of dendrite growth during development. Dev. Camb. Engl $140: 4751-4762$.

Petersen MB, Tranebjaerg L, Tommerup N, Nygaard P, Edwards H. 1987. New assignment of the adenosine deaminase gene locus to chromosome $20 \mathrm{q} 13 \times 11$ by study of a patient with interstitial deletion20q. J. Med. Genet 24:93-96.

Porfirio B, Valorani MG, Giannotti A, Sabetta G, Dallapiccola B. 1987. Ring 20 chromosome phenotype. J. Med. Genet 24:375-377.

Posmyk R, Leśniewicz R, Gogiel M, Chorąży M, Bakunowicz-Łazarczyk A, Sielicka D, Vermeesch J, Nowakowska BA. 2014. The smallest de novo deletion of $20 \mathrm{q} 11.21-\mathrm{q} 11.23$ in a girl with feeding problems, retinal dysplasia, and skeletal abnormalities. Am. J. Med. Genet A 164A:10561061.

Ravenscroft JC, Suri M, Rice GI, Szynkiewicz M, Crow YJ. 2011. Autosomal dominant inheritance of a heterozygous mutation in SAMHD1 causing familial chilblain lupus. Am. J. Med. Genet. A 155A:235-237.

Santoro C, Malan V, Bertoli M, Boddaert N, Vidaud D, Lyonnet S. 2009. 2013. Sporadic NF1 mutation associated with a de-novo 20q11.3 deletion explains the association of unusual facies, Moyamoya vasculopathy, and developmental delay, reported by Bertoli et al. in. Clin. Dysmorphol 22:42-43.

Shabtai F, Ben-Sasson E, Arieli S, Grinblat J. 1993. Chromosome 20 long arm deletion in an elderly malformed man. Genet N. J. Med 30:171173.

Shen L, Liang F, Walensky LD, Huganir RL. 2000. Regulation of AMPA receptor GluR1 subunit surface expression by a 4 . $1 \mathrm{~N}$-linked actin cytoskeletal association. J. Neurosci. 20:7932-7940.. Off. J. Soc. Neurosci.

Storm EE, Kingsley DM. 1996. Joint patterning defects caused by single and double mutations in members of the bone morphogenetic protein (BMP) family. Dev. Camb. Engl 122:3969-3979.

Temtamy SA, Aglan MS. 2008. Brachydactyly. Orphanet J. Rare Dis 3:15.

Yang W, Cao L, Liu W, Jiang L, Sun M, Zhang D, Wang S, Lo WHY, Luo Y, Zhang X. 2008. Novel point mutations in GDF5 associated with two distinct limb malformations in Chinese: brachydactyly type $\mathrm{C}$ and proximal symphalangism. J. Hum. Genet 53:368-374. 